\title{
Fuentes de Juan de Arfe para el Libro tercero de la Varia commensuración
}

\section{Juan de Arfe's Sources for the Third Book of the Varia commensuración}

José-Luis Crespo-Fajardo

Universidad de Cuenca

ECUADOR

luis.crespo@ucuenca.edu.ec

Luisa Pillacela-Chin

Investigadora independiente

ECUADOR

luisap_42@hotmail.com

[Hipogrifo, (issn: 2328-1308), 8.2, 2020, pp. 543-560]

Recibido: 11-02-2020 / Aceptado: 20-05-2020

DOI: http://dx.doi.org/10.13035/H.2020.08.02.32

Resumen. Este artículo examina el Libro tercero de la Varia commensuración de Juan de Arfe (1587), dedicado a describir medidas de animales cuadrúpedos y aves. Hemos localizado las fuentes eruditas de sus enunciados en Plinio, Aristóteles, San Isidoro y Bartholomeus Anglicus, y a partir de información de autores contemporáneos a Arfe planteamos localizaciones donde pudo ver a los animales que menciona, algunos bastante exóticos, con sus propios ojos. Atendiendo a los grabados, sugerimos posibles fuentes iconográficas y descubrimos detalles relacionados con la lógica de lo manifestado en el texto por el tratadista.

Palabras clave. Arfe; animales; arte; tratados; siglo XVI; España.

Abstract. This article examines the Third Book of the Varia commensuración by Juan de Arfe (1587), dedicated to describe measures of quadruped animals and birds. We have located the erudite sources of his statements in Pliny, Aristotle, Saint Isidore and Bartholomeus Anglicus, and, based on information from authors contemporary to Arfe, we propose locations where he could see the animals he mentions, some of them quite exotic, with his own eyes. Taking into account the 
engravings, we suggested possible iconographic sources and discovered details related to the logic of what was expressed in the text by the treatiser.

Keywords. Arfe; Animals; Art; Treaties; 16th century; Spain.

\section{INTRODUCCIÓN}

De varia commensuración para la sculptura y arquitectura, de Juan de Arfe, se publicó en Sevilla en 1587. El tratado está compuesto por cuatro libros, y en este artículo nos enfocamos en el Libro tercero, que ofrece las medidas de ciertos animales cuadrúpedos y aves.

Nos centramos en el examen de las fuentes que sirvieron a Arfe para elaborar esta sección del tratado, refiriéndonos tanto a fuentes literarias como visuales pues, aunque el tratadista demuestra poseer gran bagaje de información de textos clásicos y en los grabados se evidencian deudas de obras contemporáneas, él mismo indica que solo presenta los animales que ha visto con sus propios ojos, por lo que hemos de considerar en dónde los pudo ver.

Acerca de esta sección de la Varia se ha escrito relativamente poco, pero hay que destacar los estudios de Bonet Correa ${ }^{\top}$. Muñoz hizo una reedición del Libro tercero con un breve prólogo ${ }^{2}$, y existe una disertación de Piñero Moral sobre la estética de los animales de Juan de $\mathrm{Arfe}^{3}$. Asimismo, un estudio general se puede encontrar en la tesis doctoral de Crespo Fajardo 4 . Pese a todo, hasta ahora las fuentes eruditas de Arfe no han sido completamente desveladas, y tampoco se ha hecho una indagación exhaustiva de lo que el tratadista revela en sus palabras y en sus imágenes. Las fuentes que sacamos a colación son aquellas a las que nos ha dirigido el análisis textual e icónico de esta sección de la Varia.

\section{PROPÓSITO DEL LIBRO}

El Libro tercero de la Varia commensuración se divide en dos títulos. El primero versa acerca de animales cuadrúpedos y el segundo trata sobre aves. Arfe no atiende a "pescados, sierpes, reptiles y moscas» ${ }^{5}$ porque estos seres no contemplan medidas determinadas. Su intención es facilitar un repertorio icónico de animales correctamente proporcionados a los orfebres, a quienes dirige el tratado. En esta época era habitual que se hicieran relieves, repujados y piezas en metales preciosos con formas de animales ${ }^{6}$. El modelo del natural a veces no era accesible, por lo que se elaboraban repertorios de dibujos, como los que

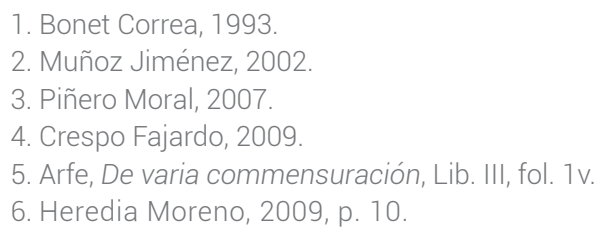


aparecen, por ejemplo, en el Álbum de Mendoza? . Por tanto, si bien es cierto que Arfe sigue el espíritu de su tiempo al emplazar la relación de animales después del libro dedicado a la figura del hombre, que en el Renacimiento se concibe como centro de la creación, también plantea concretar medidas de animales para que no haya equivocaciones al representarlos en correlación a la figura humana. Parece pensar en esta utilidad al escribir: «y todos [los animales] se han de comparar a la medida del hombre, que en la razonable disposición llega a tener de alto dos varas» ${ }^{8}$.

Igualmente, otro propósito era mostrar la realidad. Arfe declara que pretende enseñar solo aquellos animales que ha visto vivos con sus propios ojos, posiblemente porque varias de sus fuentes de consulta, antiguas y modernas, registraban indistintamente la existencia de animales mitológicos, como el unicornio o el fénix. Sin embargo, su ética parece contradecirse al constatar que algunos grabados son copia (o basan su iconografía) en las ilustraciones de Historiae animalium, del naturalista suizo Konrad Gessner, publicados a mediados del siglo XVI. Arfe no solo copió el asno, el dromedario, el lobo y algún conejo o liebre, como escribía Bonet Correa9 ${ }^{9}$. Tomó como punto de partida los grabados de la mayoría de las aves. El buitre, la garza, el águila real y las águilas blancas, el gavilán, el halcón, el azor, la abobilla, y otras muchas mantienen deudas con el tratado Avium natura de Gessner. Pese a todo, no hay que dudar de la veracidad del tratadista. Utilizar modelos ajenos no significa que no consignara únicamente los animales que observó en vivo. Aun así, es raro encontrar estos casos de copia, ya que Arfe demuestra mucha originalidad gráfica en sus tratados.

\section{LA DESCRIPCIÓN DE ANIMALES}

El tratadista inicia el libro indicando que por animal se entiende aquel provisto de espíritu de vida e instinto natural, «que tiene virtud motiva y sensitiva, porque siente y se mueve» ${ }^{10}$. En efecto, la etimología de animal la revelaba San Isidoro, por estar animado de vida y tener movimiento gracias al espíritu ${ }^{11}$. No obstante, en el tratado De proprietatibus rerum, de Bartholomeus Anglicus (Bartolomé el Inglés), encontramos esta sentencia: «Es de notar que todo animal viviente ha en sí una virtud dicha motiva que lo mueve, y la virtud sensitiva porque siente» ${ }^{12}$. Los términos «virtud motiva» y «virtud sensitiva» coinciden exactamente. Más adelante veremos más coincidencias entre el léxico de Arfe y Anglicus que no dejan duda sobre el uso que el tratadista hizo de esta enciclopedia medieval, una de las más divulgadas en Europa, con versiones en castellano.

\footnotetext{
7. Heredia Moreno, 2009.

8. Arfe, De varia commensuración, Lib. III, fol. 2r.

9. Bonet Correa, 1993, p. 63.

10. Arfe, De varia commensuración, Lib. III, fol. 1 v.

11. San Isidoro, Etimologías, p. 889.

12. Anglicus, Libro de proprietatibus rerum en romance, Pról. al Lib. XVIII.
} 
Cabe recalcar cómo Arfe clasifica cinco tipos de animales: «unos de cuatro pies, otros reptiles, otros de aire con carne y sangre, y otros sin carne ni sangre, y otros son pescados que andan por el agua» ${ }^{3}$. Al respecto hay que mencionar a Aristóteles, que estableció las primeras distinciones taxonómicas de animales, a veces con criterios variados, como el modo de desplazarse, su reproducción, si son salvajes o domésticos, o el tener o no sangre. Justamente Arfe se refiere a animales sin sangre, aludiendo a los invertebrados.

\subsection{Animales cuadrúpedos}

El relato inicia distinguiendo cuadrúpedos salvajes y domésticos. El primero de los salvajes es el león, que es «señor y rey de los animales de cuatro pies» ${ }^{14}$. Precisamente, San Isidoro indica en sus Etimologías que en latín león se interpreta como rey, por ser la más importante de las bestias ${ }^{15}$. Llama la atención que Arfe diga que este animal «alza mucho los pies y manos cuando camina» ${ }^{16}$. Aristóteles expresa que anda paso a paso, sin que el pie izquierdo pase delante del derecho ${ }^{17}$, y Anglicus indica que mueve el pie derecho antes que el izquierdo ${ }^{18}$. Tal vez la alusión provenga de una apreciación visual o sea un concepto tomado de la heráldica, donde el león pasante se representa caminando en tres patas, con una muy levantada, justo como aparece en el grabado de Arfe.

En esta sección del león se menciona el «movimiento a diámetro» que siguen los animales de cuatro patas, «que es asentar el pie antes que alce la mano de su lado» ${ }^{19}$. Este convencionalismo que parece seguir Arfe en los grabados, también lo había citado en el Libro segundo de la Varia. Está tomado de Aristóteles, que en De motu animalium explica que el cuadrúpedo «después de la pata delantera derecha mueve la izquierda trasera» ${ }^{20}$. Aristóteles apoya su discurso con diagramas geométricos que han desaparecido. Arfe, justamente, muestra un gráfico aclaratorio.

Tras el león viene el tigre, que es «animal fiero y muy ligero» ${ }^{21}$. Por ligero hemos de interpretar veloz. Plinio indica al respecto: «Dicen los Hircanos, y los indios, ser el tigre un animal de espantable ligereza» ${ }^{22}$. Es llamativo que Arfe señale que tiene círculos negros, pues no corresponde a la realidad. En el grabado se aprecian dichos círculos que le dan aspecto de leopardo, en tanto la cola muestra un penacho que los tigres no tienen (Fig. 1). Quizá experimentó una confusión iconográfica con dicho animal o esta mezcla provenga de una imprecisa interpretación visual. Se sabe que, en Madrid, ciudad en la que Arfe vivió en la década de 1570, existía una

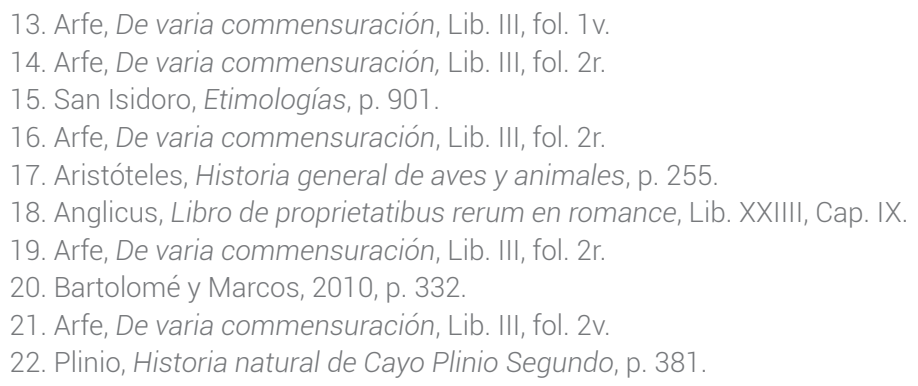


casa de fieras con animales de Felipe II. Allí pudo ver grandes felinos. Precisamente Covarrubias indica del tigre que es «animal bastante conocido, pues le hemos visto en el buen retiro de esta corte, entre otras muchas diferencias de fieras» ${ }^{23}$. Otras fuentes manifiestan que esta casa de fieras estuvo en Aranjuez ${ }^{24}$. Jerónimo Huerta, comentarista de Plinio, atestigua haber visto allí un león, un tigre, un elefante y un rinoceronte ${ }^{25}$.

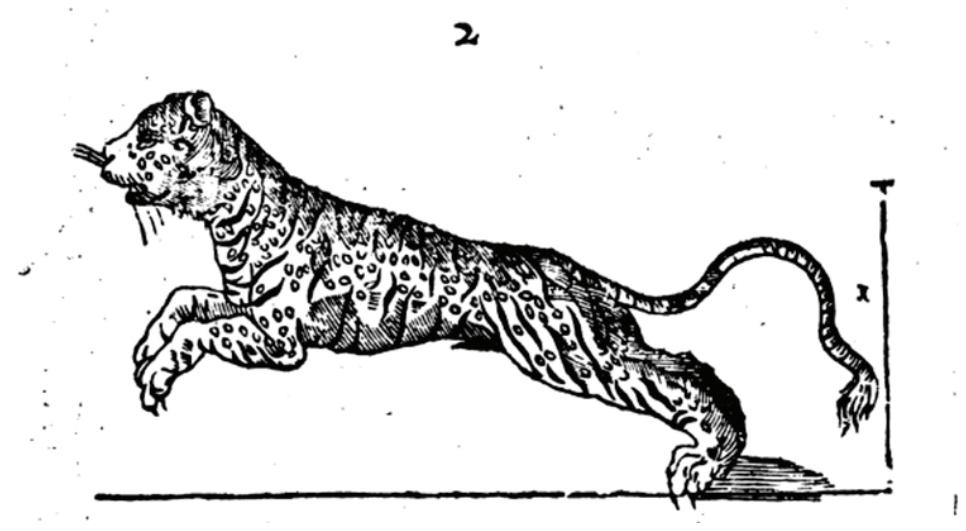

Figura 1. Tigre. De varia commensuración (1587)

A continuación, Arfe nombra al elefante, del que dice «entra en batalla con el más pujante» ${ }^{26}$. Aparte de alusiones a las guerras púnicas, esta frase puede ser inspirada por San Isidoro, que indica que es «apropiado para las acciones bélicas» ${ }^{27}, 0$ por Plinio, que apunta que es enemigo del rinoceronte ${ }^{28}$. Arfe también menciona que los elefantes no tienen «dobladura» en las piernas. En efecto, una creencia extendida aseguraba que no podía flexionar las piernas por no contar con rodillas. Covarrubias comenta: «Según opinión de muchos, el elefante duerme de pie, arrimado tan solamente al árbol, por no poder arrodillarse» ${ }^{29}$. Argote, en su Libro de la montería, lo desmiente como un sentir vulgar ${ }^{30}$.

Arfe pudo ver al elefante en Madrid, pues a Felipe II le trajeron uno «que todos vimos en Madrid, tan doméstico, que metía la mano, o trompa en las faltriqueras de los que entraban a ver, y les sacaba los dineros, o fruta, que aposta traían en ellas» ${ }^{31}$. En el grabado de la Varia se evidencia, por su complexión y envergadura, que se trataba de un elefante asiático.

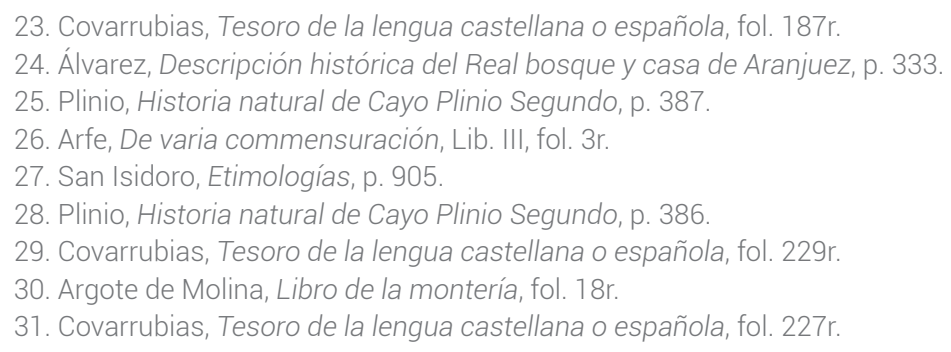


El siguiente animal es el oso. El grabado muestra seguramente un oso pardo, al cual pudo ver Arfe en su natal Castilla y León. Por otra parte, apunta ciertas curiosidades que podrían responder a apreciaciones puramente visuales, como que el oso camina con la cabeza siempre a un lado, o que se levanta con las patas traseras.

Continúa el libro con el jabalí. Al igual que al oso, Arfe pudo verlo en batidas de caza o en cautiverio. Señala que es «animal feo y cruel, de gran braveza según la cantidad de su cuerpo»32. Esto coincide enormemente con la descripción de Anglicus: "según la cantidad de su cuerpo él es muy cruel y feo»33. También dice Arfe que el jabalí no tiene miedo de los yerros que llevan los monteros. Anglicus, por su parte, explica: «sin ningún miedo de la muerte corre contra el fierro del cazador hasta se meter dentro»34. Además, Arfe escribe que el jabalí pelea con el lobo, su mortal enemigo, y levanta mucho la cabeza al pelear. Es precisamente Anglicus su fuente principal, pues expone: «pelea con el lobo, que naturalmente aborrece». Y más adelante aduce: «hiere y pelea con sus colmillos levantando la cabeza fuertemente contra el cielo» 35 .

Del lobo, Arfe comenta: «es animal arrebatado y cruel» ${ }^{36}$. Nuevamente coincide en terminología con Anglicus, que escribe: «Es animal arrebatado y cruel que desea sangre continuamente» ${ }^{37}$. Su voracidad es recalcada por Arfe al citar: «Brava persecución para el ganado / que aunque más coma de él queda goloso» ${ }^{38}$. Algo en lo que también incide Anglicus: «engaña a las ovejas que son en estos pastos y no le basta de matar una para comer, mas si le dejan mata todas las del ganado»39.

Aunque el grabado es copia de Gessner, Arfe pudo ver lobos ibéricos en puntos boscosos de la península (Fig. 2). El detalle de referir que suelen llevar la cola sin alzar, podría ser fruto de la observación.
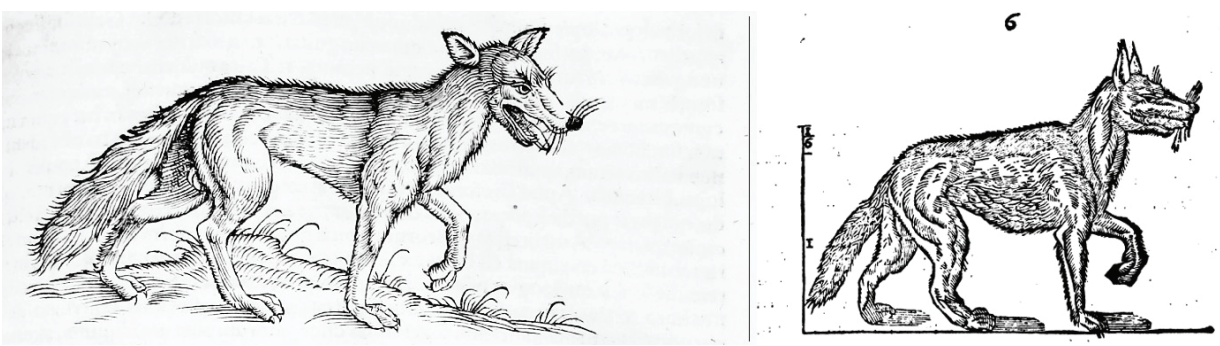

Figura 2. El lobo según Gessner (1551) y Arfe (1587)

32. Arfe, De varia commensuración, Lib. III, fol. 3v.

33. Anglicus, Libro de proprietatibus rerum en romance, Lib. XVIII, Cap. V.

34. Anglicus, Libro de proprietatibus rerum en romance, Lib. XVIII, Cap. V.

35. Anglicus, Libro de proprietatibus rerum en romance, Lib. XVIII, Cap. V.

36. Arfe, De varia commensuración, Lib. III, fol. 4r.

37. Anglicus, Libro de proprietatibus rerum en romance, Lib. XVIII, Cap. IXVI.

38. Arfe, De varia commensuración, Lib. III, fol. 4r.

39. Anglicus, Libro de proprietatibus rerum en romance, Lib. XVIII, Cap. IXVI. 
La sección de cuadrúpedos domésticos y de carga comienza con el caballo. El grabado muestra lo que podría ser un caballo andaluz que flexiona la pata derecha (Fig. 3). La pose es un convencionalismo propio de la heráldica que se refleja, por ejemplo, en el Tratado de la caballería de la jineta ${ }^{40}$, en Decades de la description, forme, et vertu naturelle des animaul $x^{41}$, uno de los primeros tratados de zoología del Renacimiento, o en el grabado de Durero «El caballero, la muerte y el diablo» (1513). En cuanto a la descripción, Arfe se detiene en su variedad de colores, algo que también hace San Isidoro con profusión ${ }^{42}$.
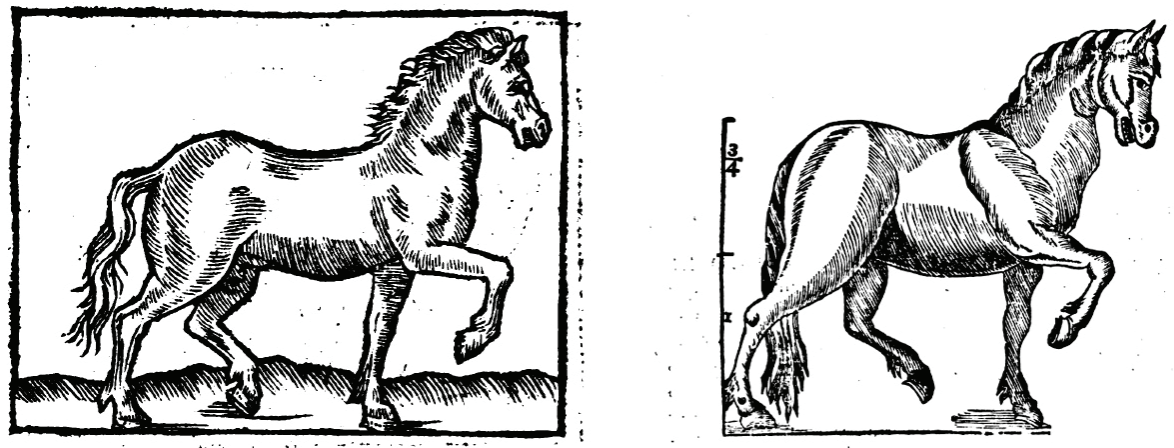

Figura 3. El caballo según Aneau (1549) y Arfe (1587)

Del asno, Arfe comenta que es "animal simple y perezoso» ${ }^{43}$. Nuevamente coincide con Anglicus, que escribe: «Es animal simple y perezoso, y por ello fue él fácilmente sujeto al servicio humano y domado» ${ }^{44}$. Es extraño que Arfe diga que tiene «ojos hundidos». La explicación la da Anglicus al referir que, según Aristóteles y Avicena, el cuervo es enemigo del asno y trata de picarle en los ojos, pero el asno lo evita gracias a la profundidad de los mismos ${ }^{45}$. En cuanto al grabado, es copia de Gessner.

Los grabados del camello y dromedario también se asemejan a los de Gessner. Del dromedario resulta extraño que Arfe escriba que tiene «una corcova grande y peluda, y en el pecho otra» ${ }^{46}$, pero Anglicus explica que estos seres: «han una (joroba) en las espaldas do son cargados y otra en el pecho sobre que duermen» ${ }^{47}$. Esa era la creencia popular. El que Anglicus es la fuente de Arfe se revela también cuando el tratadista indica que el camello posee «los pies hendidos, y en la hendi-

40. Aguilar, Tractado de la caballería de la jineta.

41. Aneau, Decades de la description, forme, et vertu naturelle des animaulx.

42. San Isidoro, Etimologías, pp. 897-899.

43. Arfe, De varia commensuración, Lib. III, fol. 5 r.

44. Anglicus, Libro de proprietatibus rerum en romance, Lib. XVIII, Cap. VI.

45. Anglicus, Libro de proprietatibus rerum en romance, Lib. XVIII, Cap. VI.

46. Arfe, De varia commensuración, Lib. III, fol. 5v.

47. Anglicus, Libro de proprietatibus rerum en romance, Lib. XVIII, Cap. XVII. 
dura tiene un cuero como los ansarones» ${ }^{48}$. Justamente Anglicus indica que tiene los pies hendidos, «y en la hendedura va un cuero a la manera de los ansarones» ${ }^{49}$.

Cabe preguntar dónde pudo ver Arfe a estos animales. Covarrubias nos da una pista al definir al camello: «De Orán los suelen traer a España, y yo he visto algunos» ${ }^{50}$. También Jerónimo Huerta consigna: «los que tiene el Rey don Felipe nuestro señor en Aranjuez, donde ya se crían muchos, no los ocupan sino en trabajos viles, porque llevan mucha carga» ${ }^{51}$.

La sección de animales con cuernos se abre con el toro, al que Arfe vería en los campos o en las lidias de la época. Al ciervo, por su parte, pudo observarlo vivo en monterías. De él menciona: «cuando huye vuelve la cabeza de rato en rato, para ver quién le sigue» ${ }^{52}$. Esta cita recuerda a Plinio, que indica que los ciervos: «siempre cuando huyen se detienen, y estando quietos miran atrás, y si sienten cerca los perros, vuelven a favorecerse de su huida»53. Por otro lado, Arfe expone que en cada cuerno tiene habitualmente cinco puntas, lo cual podría ser una observación personal, ya que en esto contradice a Plinio, que señala que la cornamenta de los ciervos puede llegar a seis ramos ${ }^{54}$. Hay una cierta semejanza icónica entre el ciervo de Arfe y el del grabado de Durero «San Eustaquio» (1501) (Fig. 4).
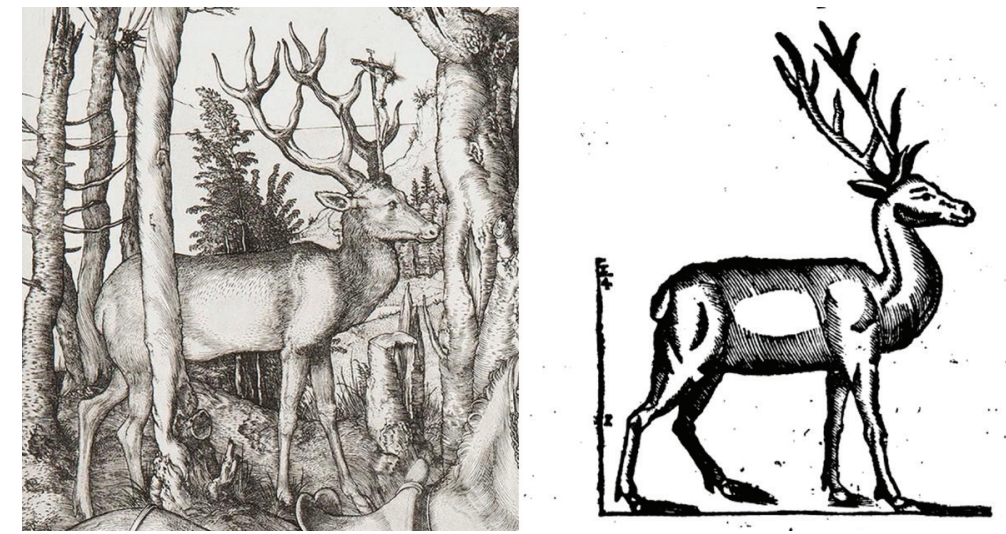

Figura 4. El ciervo según Durero (1501) y Arfe (1587)

Sobre el carnero, Arfe asevera: «duerme con la cabeza elevada» ${ }^{55}$. Esta creencia popular la refiere Jerónimo Huerta tomada de Claudio Eliano ${ }^{56}$. Anglicus también

48. Arfe, De varia commensuración, Lib. III, fol. 5r.

49. Anglicus, Libro de proprietatibus rerum en romance, Lib. XVIII, Cap. XVII.

50. Covarrubias, Tesoro de la lengua castellana o española, fol. $124 \mathrm{r}$.

51. Plinio, Historia natural de Cayo Plinio Segundo, p. 384.

52. Arfe, De varia commensuración, Lib. III, fol. 7r.

53. Plinio, Historia natural de Cayo Plinio Segundo, p. 436.

54. Plinio, Historia natural de Cayo Plinio Segundo, p. 437

55. Arfe, De varia commensuración, Lib. III, fol. $7 \mathrm{v}$.

56. Plinio, Historia natural de Cayo Plinio Segundo, p. 486. 
recoge que los carneros «duermen la cabeza elevada». ${ }^{57}$ En cuanto al cabrón, Arfe asegura que ve de noche más que otros animales. Esta información está justificada en Plinio, que aduce sobre las cabras y chivos: «Dícese que ven de noche tanto como de día»58.

Acerca del rinoceronte, el grabado es similar al que hizo Durero en 1515, aunque es probable que la fuente directa sea Gessner, que lo reproduce y con él guarda más parecido. Que sea una copia no significa que Arfe no haya visto un rinoceronte. Varios testimonios certifican que alrededor de 1581 llegó a España un rinoceronte de la isla de Java, como regalo a Felipe II de Alonso Gaitán, gobernador de Java, en nombre del reyezuelo indígena Musuturé Fusuma ${ }^{59}$. Lo denominaron «abada», vocablo en portugués para el rinoceronte hembra, y se exhibió en Madrid, donde una calle aún lleva su nombre ${ }^{60}$. Covarrubias lo llama bada y dice haberlo visto con el cuerno aserrado y ciego para que no hiciese daño, añadiendo que mató a uno de sus cuidadores ${ }^{61}$. Diego de Funes declara haberlo visto en la Corte en $1585^{62}$. Jerónimo Huerta también lo vio, aunque recalca: «no tiene cuerno en el principio del lomo, como dijo Conrado [...], sino solo uno, aunque este le tenía cortado, pero veíase muy bien el asiento de donde salía» ${ }^{63}$.

La cita de Huerta deja entrever una prueba de que Arfe observó al animal, pues el grabado de la Varia no presenta el pequeño cuerno al inicio del lomo que sí aparece en las imágenes de Durero y Konrad Gessner (Fig. 5). Arfe suprimió ese detalle por no hallarlo en el auténtico rinoceronte.

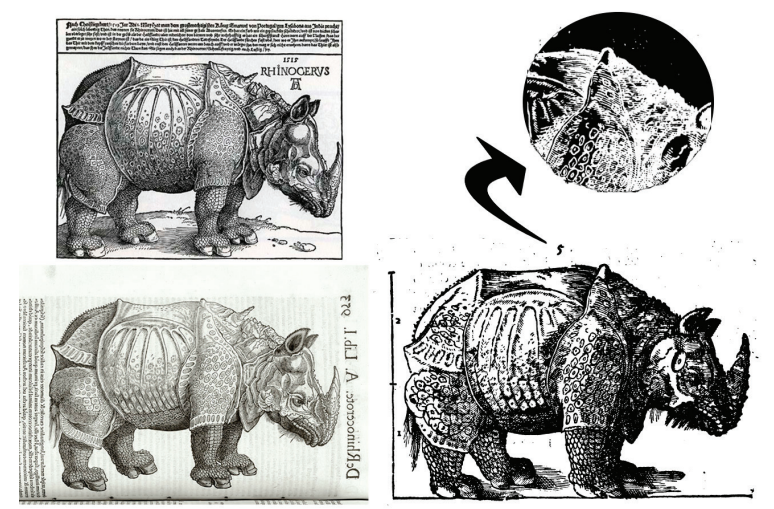

Figura 5. El rinoceronte según Durero (1515), Gessner (1551) y Arfe (1587). Ausencia de cuerno en el lomo

57. Anglicus, Libro de proprietatibus rerum en romance, Lib. XVII, Cap. I.

58. Plinio, Historia natural de Cayo Plinio Segundo, p. 489.

59. Mena, 1989, pp. 58-59.

60. Bonet Correa, 1993, p. 81

61. Covarrubias, Tesoro de la lengua castellana o española, fol. 78r.

62. Aristóteles, Historia general de aves y animales, pp. 270-271.

63. Plinio, Historia natural de Cayo Plinio Segundo, p. 387. 
En relación al texto descriptivo, es llamativa la frase «nada y corre veloz y sueltamente» ${ }^{64}$. Se sabe que el rinoceronte indio y el de Java nadan, aunque sería raro que Arfe fuera testigo de ello. En todo caso, la especie de rinoceronte que conoció sería la propia de la isla de Java. Arfe dice que es animal nacido en el oriente y le da dos varas de alto (1'68 m.). Ciertamente, el rinoceronte de Java es más pequeño que el indio. La hembra carece de cuerno o lo tiene muy pequeño, por lo que podríamos cuestionar que su cuerno fuera cortado.

El apartado dedicado a los perros se inicia con el elogio de la lealtad a sus amos, muy en consonancia con Plinio, que señala que el perro es el más fiel de los seres que conviven con el hombre ${ }^{65}$. Menciona primero al galgo, «mortal enemigo de las liebres» ${ }^{66}$. Los cazadores de la época los empleaban. Jerónimo Huerta refiere que en Castilla solamente con galgos matan a las liebres ${ }^{67}$. Del podenco Arfe indica que tiene la cola cortada porque conviene así para la caza. Se refiere a la práctica de amputar el rabo (caudectomía). Tradicionalmente se elimina un tercio de su longitud porque con el rabo la silueta del perro hace una línea recta señalando la presencia de la caza. Esto se llama «marcar la muestra», y por el modo en que se tensa los cazadores pueden reconocer de qué tipo de caza se trata68.

De los gozques, Arfe comenta que hay muchas razas y añade que suelen ser «mantenidos de gente pobre y común» ${ }^{69}$. Este curioso dato también aparece en Covarrubias: "los gozques son unos perrillos que crían gente pobre y baja» ${ }^{70}$. Arfe refiere luego al mastín, perro de agua y lebrel. Del último dice: «Estos lebreles pelean en defensa de su señor hasta morir o vencer» ${ }^{71}$. Los lebreles se usaban en la montería de venados, y Jerónimo Huerta los llama también «perros de ayuda», porque pelean en defensa de sus amos ${ }^{72}$. Su icono recuerda al del citado grabado de Durero «San Eustaquio» (1501).

La sección de animales pequeños contiene al puercoespín, la liebre, el conejo, la ardilla y el erizo, animales comunes en España. Del erizo, Arfe recalca que «tiene talle de lechón, y no tiene espinas en la cara, ni en las manos, y barriga» ${ }^{73}$. Su fuente es, posiblemente, el Dioscórides de Andrés de Laguna, donde se señala que el erizo «parece lechón; el cual tiene todo el cuerpo armado de muy agudas espinas, salvo el hociquillo, el vientre y los pies» ${ }^{74}$.

64. Arfe, De varia commensuración, Lib. III, fol. 7v.

65. Plinio, Historia natural. Libros VII-IX, p. 179.

66. Arfe, De varia commensuración, Lib. III, fol. 8 r

67. Plinio, Historia natural de Cayo Plinio Segundo, p. 509.

68. Sociedad de Cazadores, Tesoro de los perros de caza, p. 19.

69. Arfe, De varia commensuración, Lib. III, fol. 8v.

70. Covarrubias, Tesoro de la lengua castellana o española, fol. 37r.

71. Arfe, De varia commensuración, Lib. III, fol. 9r.

72. Plinio, Historia natural de Cayo Plinio Segundo, p. 463.

73. Arfe, De varia commensuración, Lib. III, fol. 9v.

74. Laguna, Acerca de la materia medicinal y de los venenos mortíferos, p. 123. 
El título termina con el raposo (el zorro). Arfe declara que tiene las piernas más largas en la parte derecha que en la izquierda. Este dato fabuloso aparece en Anglicus: «[el raposo] siempre va a través cojeando: sus piernas son más luengas de la parte derecha que de la izquierda» ${ }^{75}$.

\subsection{Aves}

El título segundo se dedica a las aves, las cuales «se nombran animales sin guía, porque no dejan rastro en el aire por donde pasan» ${ }^{76}$. La referencia podría ser Anglicus, que refiere: «Las aves son dichas casi sin vía, como Isidoro dice, porque su vida no es determinada en el aire. Cuando ellas vuelan dividen el aire con sus alas. Cuando son pasadas el aire cierra. Así que no queda ninguna senda ni vía, por donde han pasado» 77 . O podría ser San Isidoro: «Se les llama aves porque no poseen caminos previamente establecidos, sino que discurren en su vuelo por rutas $\sin$ trazar (avia)» ${ }^{78}$.

La descripción comienza con el águila real, a la que Arfe considera la reina de las aves porque comparte con otras su comida. Para Anglicus, el águila es, entre las aves, «reina más liberal», y refiere que, según Plinio, «cuando toma la caza no la come sola, sino que haya hambre, mas la pone a comer ante las aves que son en su compañía, después que ella haya tomado su debida porción» ${ }^{79}$. Esta cualidad se refleja en la emblemática. Covarrubias menciona un jeroglífico de la benignidad del generoso, donde un águila se apacienta junto a otras aves ${ }^{80}$.

Del águila, Arfe señala que tiene muy desarrollado el sentido visual «porque volando ve nadar los peces/ y se baja a tomarlos muchas veces» ${ }^{81}$. La fuente original es San Isidoro, que aduce que el águila toma su nombre de la agudeza de su vista, y cuando sobrevuela el mar «ve nadar a los pececillos, sobre los que se precipita a manera de un rayo y, haciendo presa en ellos, vuela hacia la costa»82. No obstante, Arfe pudo leer los mismos enunciados en Anglicus: «Ella ve los pequeños peces que van por los mares y ríos y se deja dentro caer como una saeta, y arrebata el pez y lo caza arriba por lo comer» ${ }^{83}$. Así, cuando seguidamente Arfe indica que el águila «tiene tan gran vista que mira el sol sin que la ofenda» ${ }^{84}$, su fuente pudo ser Anglicus, que expresa: «ella ve el sol en su círculo sin pasar detrimento en los ojos»85,

\footnotetext{
75. Anglicus, Libro de proprietatibus rerum en romance, Lib. XIX, Cap. CVII.

76. Arfe, De varia commensuración, Lib. III, fol. 10r.

77. Anglicus, 1529, Pról., Lib. XII.

78. San Isidoro, Etimologías, p. 939.

79. Anglicus, Libro de proprietatibus rerum en romance, Lib. XII, Cap. II.

80. Covarrubias, Tesoro de la lengua castellana o española, fol. 17r.

81. Arfe, De varia commensuración, Lib. III, fol. 10r.

82. San Isidoro, Etimologías, p. 939.

83. Anglicus, Libro de proprietatibus rerum en romance, Lib. XII, Cap. II.

84. Arfe, De varia commensuración, Lib. III, fol. 10r y v.

85. Anglicus, Libro de proprietatibus rerum en romance, Lib. XII, Cap. II.
} 
aunque la referencia original es San Isidoro: «Cuentan también que mira de frente los rayos del sol sin cerrar los ojos» ${ }^{86}$.

Prosigue Arfe aludiendo al quebrantahuesos, pigargos y melanetos, que llama aguilillas blancas. Luego nombra al buitre y subraya que nunca vuela ni caza por la mañana «porque es de algunas aves temeroso»87. Aristóteles ya notó que «caza el buitre desde mediodía hasta la noche, y todo el demás tiempo se está metido el pico debajo de las alas» ${ }^{88}$. No obstante, Arfe pudo tomar el dato de Anglicus: «Su cazar es de mediodía hasta la noche y se reposa de mañana hasta mediodía» 89 . Que el buitre teme a otras aves puede ser una licencia de Arfe o que lo haya observado personalmente, pues existen diversas especies de buitre en España. Por otro lado, Arfe dice del buitre que sigue a la guerra para comerse los cuerpos muertos. La fuente del dato es Plinio, aunque Anglicus recoge el informe: «siguen las guerras y batallas, o lugares donde se hacen por se hartar de la carne de los hombres y caballos» ${ }^{90}$.

Sobre el avestruz, Arfe escribe, aludiendo a sus plumas: «solo sirven para adorno de capitanes y soldados» ${ }^{91}$. Su referencia parece ser Plinio: «sus plumas adornan las celadas y morriones de la guerra» ${ }^{92}$. El tratadista también indica: «Tiene pies de animal, no de uña entera / sino abierta a la forma de venado» ${ }^{93}$. La fuente puede ser nuevamente Plinio: «Tienen las uñas semejantes a las del ciervo, con las cuales pelean ${ }^{94}$. Enigmáticamente, Arfe dice que el avestruz «mira muchas veces de noche a las estrellas» ${ }^{95}$. La explicación la revela Anglicus: «y cuando viene el tiempo que el avestruz debe poner sus huevos levanta sus ojos contra el cielo, y mira las estrellas llamadas pléyades, sin las cuales no puede poner» ${ }^{96}$. En cuanto al icono del avestruz, es muy semejante al que aparece en un grabado de las Fábulas de Esopo de Eduwaert de Dene ${ }^{97}$ (Fig. 6), ilustración que sería también fuente de inspiración del emblema «Spiritus Durissima Coquit», de Joachim Camerarius ${ }^{98}$.

86. San Isidoro, Etimologías, p. 939.

87. Arfe, De varia commensuración, Lib. III, fol. 10v.

88. Aristóteles, Historia general de aves y animales, p. 50.

89. Anglicus, Libro de proprietatibus rerum en romance, Lib. III, Cap. XXXVI.

90. Anglicus, Libro de proprietatibus rerum en romance, Lib. III, Cap. XXXVI.

91. Arfe, De varia commensuración, Lib. III, fol. 11 r.

92. Plinio, Historia natural de Cayo Plinio Segundo, p. 667.

93. Arfe, De varia commensuración, Lib. III, fol. 11r.

94. Plinio, Historia natural de Cayo Plinio Segundo, p. 667.

95. Arfe, De varia commensuración, Lib. III, fol. 11 r.

96. Anglicus, Libro de proprietatibus rerum en romance, Lib. III, Cap. XXXIV.

97. De Dene, De Warachtighe Fabulen der Dieren, p. 212.

98. Camerarius, Symbolorum et emblematum ex animalibus quadrupedibus. 

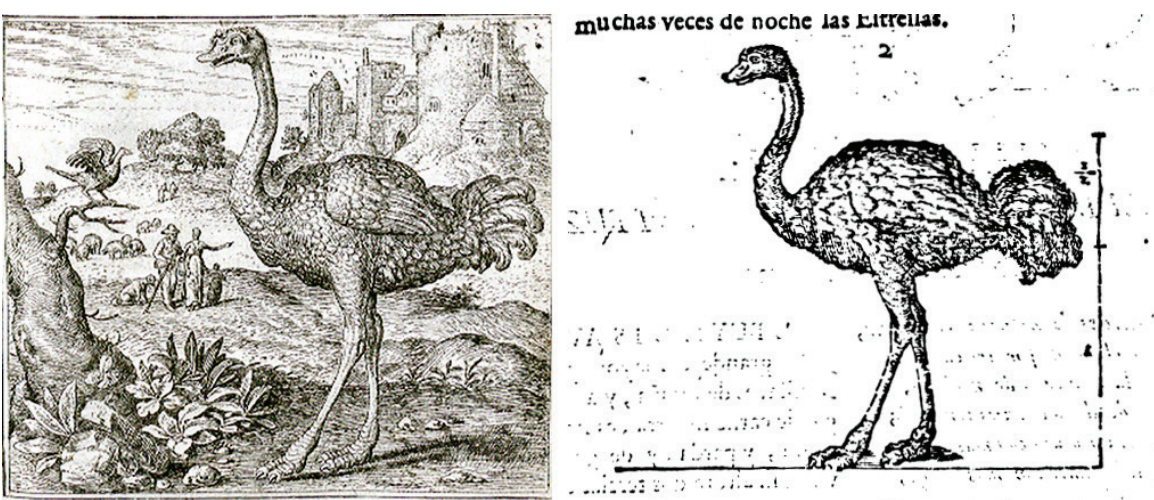

Figura 6. El avestruz según Eduwaert de Dene (1567) y Arfe (1587)

¿Dónde pudo Arfe observar avestruces? Jerónimo Huerta declara que a España se habían traído algunos, pero no tuvieron descendencia99. Además, hacia 1585 había en Madrid una casa de aves con «avestruces, cisnes, ánsares, paletos, que eran unas aves blancas, faisanes, gallinas de Guinea, pavones o pavos reales, pavos del país, gallinas, pollas y capones, que se engordaban con leche, y servían al regalo de los reyes» 100 .

Del gavilán, Arfe dice que es «ave real, traída de manos de señores», y que «si algún ave se le rinde, la deja libre» ${ }^{101}$. Se sabe que en el medievo solo los nobles podían criar gavilanes ${ }^{102}$. Diego de Funes nos indica la procedencia de las otras referencias: «San Isidoro la celebra por ave real, y excelente: El gavilán (dice) es ave real [...] Y no es tanta su ferocidad, que no tenga mucho de piedad, y mansedumbre, pues como dice Plinio [...] suelta por la mañana el pájaro que tuvo en las uñas la noche antes para dormir» ${ }^{103}$.

Arfe cita aves como el azor y el halcón, cernícalos, alcotanes, esparveles y esmerejones. Menciona al sirguero, cogujada y gorrión. Del cuervo escribe «dicen que vive mucho» ${ }^{104}$. En efecto, Covarrubias comenta que el cuervo, según Hesíodo, al que alude Plinio, tiene una vida larga ${ }^{105}$. Diego de Funes glosa: «Vive el cuervo muchos años más que la Fénix» ${ }^{106}$, calculándole más de cien años.

Arfe nombra al grajo, calandria, faisán y perdiz. Luego a las «aves de agua», mencionando la garza y la grulla. De la última dice: «duerme sobre un pie, y una piedra en el otro» ${ }^{107}$. Plinio escribe que las grullas, en guerra con los pigmeos, por

99. Plinio, Historia natural de Cayo Plinio Segundo, p. 667

100. Álvarez, 1804, pp. 220-225

101. Arfe, De varia commensuración, Lib. III, fol. 11 v.

102. Bastús, 1833, p. 23.

103. Aristóteles, Historia general de aves y animales, p. 21.

104. Arfe, De varia commensuración, Lib. III, FOL. 12r.

105. Covarrubias, Tesoro de la lengua castellana o española, fol. 176v

106. Aristóteles, Historia general de aves y animales, pp. 61-62.

107. Arfe, De varia commensuración, Lib. III, fol. 12v. 
las noches vigilan. Son «escuchas y centinelas, las cuales sustentan con un pie una piedra, para que, si con el sueño la afloja y se cae, muestre su indiligencia ${ }^{108}$. En el grabado Arfe tuvo el detalle de incluir la piedra en la pata de la grulla. Se trata de un motivo muy habitual en la emblemática renacentista, símbolo de la vigilancia y la prudencia ${ }^{109}$. Aparece, por ejemplo, en el Dialogo dell'imprese de Paolo Giovio ${ }^{110}$ (Fig. 7). Sin embargo, Arfe no alude en el texto a su significado emblemático. En general, en el Libro tercero de la Varia no hay apenas referencias a simbolismos alegóricos, pese a que el tema estaba en su ámbito de interés, ya que en las grandes custodias que ejecutó había abundante presencia de simbología animal. En su opúsculo Descripción de la traza y ornato de la custodia de plata de la sancta iglesia de Sevilla (1587), relaciona el significado de empresas con leones, cuervos, cigüeñas, liebres, ovejas, y animales fabulosos como el Fénix ${ }^{111}$. Es indiscutible que estaba interesado en la emblemática, pero en este Libro tercero de la Varia su intención parece haber sido solo mostrar animales desde el concepto de historia natural manejado en la época.

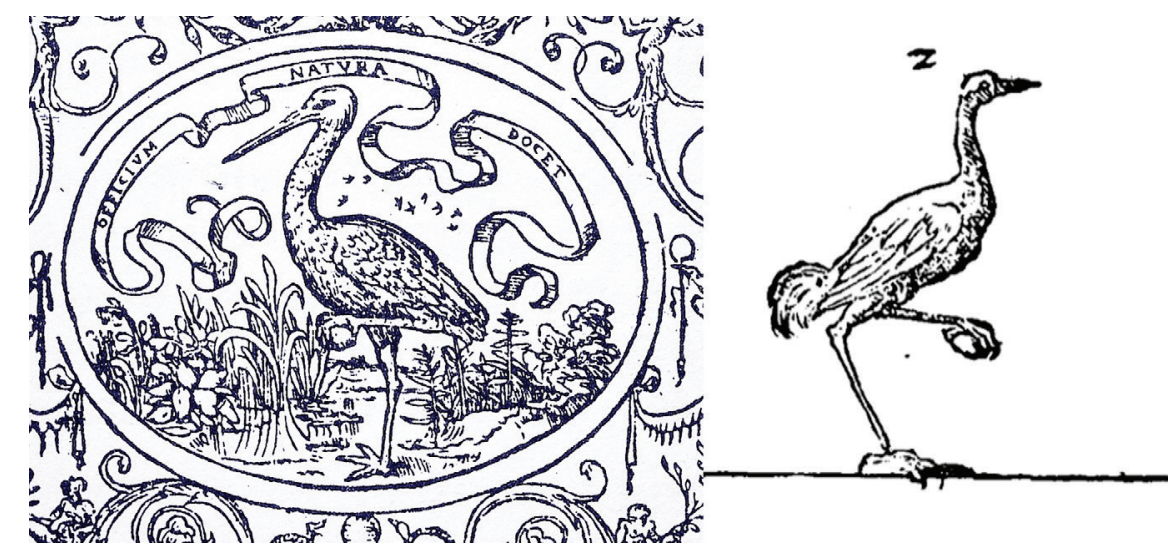

Figura 7. La grulla sostiene una piedra con su pata alzada en Giovio (1574) y en Arfe (1587)

Prosigue Arfe con la cigüeña, cisne, gaviota, ansarón, mergo, lar, anadón, papagayo, pavón, pico, mochuelo y abobilla. La imagen del pavón no se basa en Gessner, que lo muestra con la cola desplegada. Su perfil es coincidente con el de las Fábulas de Esopo de Eduwaert de Dene antes mencionadas (Fig. 8) $)^{112}$.

108. Plinio, Historia natural de Cayo Plinio Segundo, p. 721

109. García Arranz, 2002, p. 22

110. Giovio, Dialogo dell'imprese militari et amorose, pp. 105-107.

111. Andrés González, 2015.

112. De Dene, De Warachtighe Fabulen der Dieren, p. 8. 

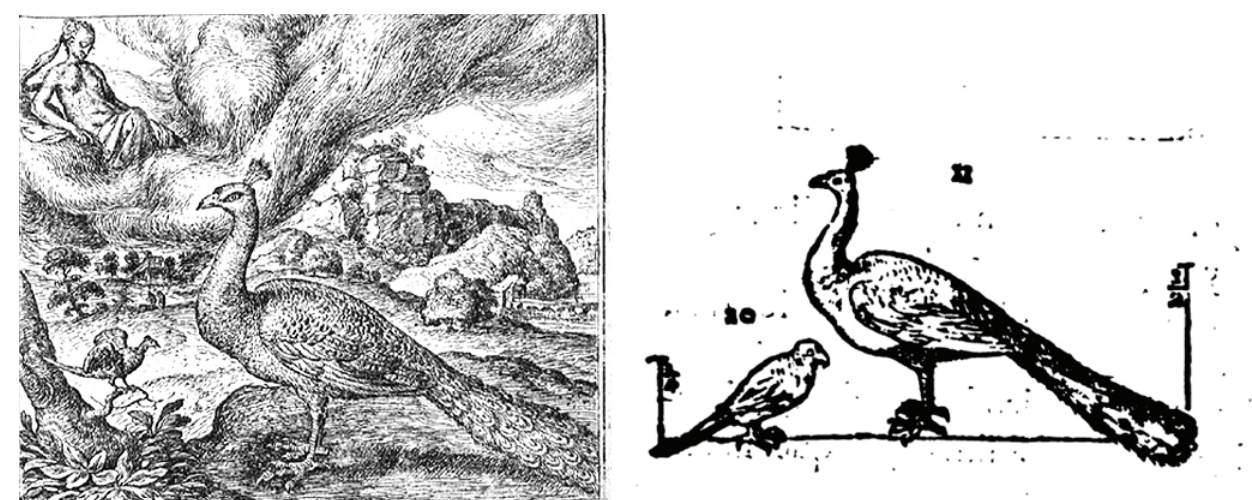

Figura 8. El pavo real en según Eduwaert de Dene (1567) y Arfe (1587)

Al gallipavo lo califica de ave perezosa, pero hemos de entender pesada y lenta. Jerónimo Huerta explica que el gallipavo es llamado «gallo o pavo indiano» y que es "grandísimo de cuerpo» ${ }^{113}$. Esta especie vino a Europa con las primeras expediciones españolas en América.

Patricia Andrés advirtió que, en la portada de la segunda edición del Quilatador (1598), aparecen un gallipavo y un elefante, indicando que son «prácticamente iguales» a los de la Varia ${ }^{114}$. En realidad, el elefante es diferente, pero el gallipavo si es igual. Andrés sugiere que Arfe simboliza con el gallipavo el trabajo humilde de Felipe $\mid I^{115}$. Para nosotros Arfe simplemente alude a la amplitud geográfica del imperio español, con el gallipavo representativo de América y el elefante de Asia.

Tras el búho, Arfe dice de la golondrina que pocas veces se la ve en pie y que vuela mucho. El dato está en San Isidoro, que apunta: «no toma sus alimentos posándose en el suelo, sino que es en el aire donde encuentra y consume su comida» ${ }^{116}$. Anglicus, de donde Arfe pudo tomar la referencia, repite: «La golondrina es así llamada porque siempre vuela en el aire: volando ella toma su vianda; y no estando queda, como dice Isidoro» ${ }^{117}$.

Enseguida Arfe nombra al tordo, paloma y gallo. Del milano dice que es gran cazador de pollos. Anglicus, su posible fuente, refiere «no osa tomar las aves salvajes, mas solamente persigue las domésticas, como pollos que son a mal recaudo» ${ }^{178}$. También Jerónimo Huerta nos habla de un emblema de esta ave que, por perseguir a los pollos de las gallinas, representa a los atrevidos y ladrones ${ }^{119}$.

\footnotetext{
113. Plinio, Historia natural de Cayo Plinio Segundo, pp. 717-718.

114. Andrés González, 2009, p. 136.

115. Andrés González, 2009, p. 137.

116. San Isidoro, Etimologías, p. 951

117. Anglicus, Libro de proprietatibus rerum en romance, Lib. III, Cap. XXII.

118. Anglicus, Libro de proprietatibus rerum en romance, Lib. III, Cap. XVII.

119. Plinio, Historia natural de Cayo Plinio Segundo, p. 692.
} 


\section{CONCLUSIONES}

Al examinar el contenido del Libro tercero de la Varia, hemos constatado que Arfe bebe principalmente de fuentes de la antigüedad (Aristóteles, Plinio, Dioscórides) y del medievo (San Isidoro y Anglicus), localizando y analizando las referencias explícitas. Aunque San Isidoro es una fuente constante para Anglicus, y este último es sin duda fuente directa para Arfe, no debemos descartar que el tratadista español manejara alguna copia en romance de las Etimologías. Asimismo, cierta información puede haberla referido de oídas, fruto de conversaciones con eruditos del ámbito eclesiástico y secular.

Evidenciamos también que los animales que cita son comunes en la península ibérica, por lo que seguramente pudo verlos con sus propios ojos. Hemos expuesto también dónde pudo observar animales exóticos, gracias a informes contemporáneos que indican su presencia en la España de la época.

Sobre los grabados, se basó principalmente en Gessner, en el Esopo de Eduwaert de Dene y tal vez en estampas de Durero. El cuidado con que Arfe los supervisó se aprecia en la grulla, que incluye una piedra en la pata, o en el rinoceronte, donde se suprime el cuerno que en el lomo le colocaran Durero y Gessner.

\section{BiBLIOgRAFÍA}

Aguilar, Pedro de, Tractado de la caballería de la jineta, Sevilla, Hernando Díaz, 1572.

Álvarez de Quindós y Baena, Juan Antonio, Descripción histórica del Real bosque y casa de Aranjuez, Madrid, Imprenta Real, 1804.

Andrés González, Patricia, «Alegoría y emblemática en la platería renacentista: las portadas del Quilatador de Juan de Arfe», Boletín del Seminario de Estudios de Arte y Arqueología, 75, 2009, pp. 127-138.

Andrés González, Patricia, «"Hieroglificos y empresas" en la custodia hispalense de Juan de Arfe», Laboratorio de Arte, 27, 2015, pp. 113-132.

Aneau, Barthélemy, Decades de la description, forme, et vertu naturelle des animaulx, tant raisonnables, que brutz, Lyon, Balthazar Arnoullet, 1549.

Anglicus, Bartholomeus, Libro de proprietatibus rerum en romance: Historia natural do se trata[n] las p[ro]piedades d[e] todas las cosas: va aco[m]pañada de gra[n] des secretos de astrología, medicina, cirugía, geometría, música y cosmografía, Toledo, Giovanni Tomaso Fabio, 1529.

Arfe y Villafañe, Juan de, De varia commensuración para la esculptura y arquitectura, Sevilla, Andrea Pescioni y Juan de León, 1587. 
Argote de Molina, Gonzalo, Libro de la montería que mando escrebir el muy alto y muy poderoso rey don Alonso de Castilla y de León, último deste nombre, Sevilla, Andrea Pescioni, 1582.

Aristóteles, Historia general de aves y animales. Traducido (y comentado) por Diego de Funes y Mendoza, Valencia, Pedro Patricio Mey, 1621.

Bartolomé, Rosana, y Marcos, Alfredo (eds.), Aristóteles. Obra biológica (De Partibus Animalium, Motu Animalium, De Incessu Animalium), Madrid, Luarna, 2010.

Bastús, Vicente Joaquín, Diccionario histórico enciclopédico, Barcelona, Roca, 1833.

Bonet Correa, Antonio, Figuras, modelos e imágenes en los tratadistas españoles, Madrid, Alianza, 1993.

Camerarius, Joachim, Symbolorum et emblematum ex animalibus quadrupedibus desumtorum centuria altera collecta, Nuremberg, P. Kaufmann, 1595.

Covarrubias, Sebastián, Tesoro de la lengua castellana o española, Madrid, Melchor Sánchez, 1674.

Crespo Fajardo, José Luis, Preceptiva gráfica de Juan de Arfe, Sevilla, Universidad de Sevilla, 2009.

De Dene, Eduwaert, De Warachtighe Fabulen der Dieren, Brujas, Pieter de Clerck, Brujas, 1567.

García Arranz, José Julio, «Documento histórico y exaltación simbólica en un grabado de Enea Vico: el ejército del emperador Carlos V cruzando el Elba cerca de Mühlberg», Norba-Arte, 12, 2002, pp. 5-27.

Giovio, Paolo, Dialogo dell'imprese militari et amorose, Lyone, Guglielmo Rovillo, 1574.

Heredia Moreno, María del Carmen, «El álbum Mendoza de la Fundación Lázaro Galdiano, de repertorio de modelos a objeto de coleccionismo», en Congreso Internacional Imagen Apariencia, Murcia, Universidad de Murcia, 2009, s. p.

Isidoro, San, Etimologías, Madrid, Biblioteca de Autores Cristianos, 2004.

Laguna, Andrés de, Pedacio Dioscórides anazarbeo, Acerca de la materia medicinal y de los venenos mortíferos, Salamanca, Mathias Gast, 1563.

Mena, José María de, Leyendas y misterios de Madrid, Madrid, Plaza \& Janés, 1989.

Muñoz Jiménez, Isabel, Bestiario de Juan de Arfe, Madrid, Medusa, 2002.

Piñero Moral, Ricardo, «Estética de los animales: una lectura imaginaria de la "varia conmensuración" de Juan de Arfe y Villafañe», en Actas de las VI y VII Jornadas de Hispanismo filosófico, Madrid, Fundación Ignacio Larramendi, 2007, pp. 99-108. 
Plinio, Historia natural de Cayo Plinio Segundo. Traducido por Jerónimo de Huerta, Madrid, España, Luis Sánchez, 1624.

Plinio, Historia natural. Libros VII-IX, Madrid, Gredos, 2003.

Sociedad de Cazadores, Tesoro de los perros de caza, o sea arte de conocer las razas de los perros, elección de los de caza, Madrid, Imp. Ramón Campuzano, 1858. 